\title{
Outcome following Percutaneous Trans-hepatic Biliary Drainage (PTBD) in carcinoma gallbladder: A prospective observational study
}

\section{Vanji Nathan Subramani}

Post Graduate Institute of Medical Education and Research

Mohanasundaram Avudaiappan

Post Graduate Institute of Medical Education and Research

Thakur Deen Yadav

Post Graduate Institute of Medical Education and Research

Hemanth Kumar

Post Graduate Institute of Medical Education and Research

Vishal Sharma

Post Graduate Institute of Medical Education and Research

Harshal Mandavdhare

Post Graduate Institute of Medical Education and Research

Ujjwal Gorsi

Post Graduate Institute of Medical Education and Research

Harjeet Singh ( $\nabla$ harjeetsingh1982@gmail.com )

PGIMER Chandiagrh https://orcid.org/0000-0002-0748-9473

\section{Research Article}

Keywords: gallbladder cancer, biliary drainage, complication, quality of life, jaundice

Posted Date: March 1st, 2021

DOI: https://doi.org/10.21203/rs.3.rs-171582/v1

License: (1) (1) This work is licensed under a Creative Commons Attribution 4.0 International License. Read Full License 


\section{Abstract}

Introduction: Percutaneous Biliary drainage (PTBD) is required as palliation and optimization for surgery or chemotherapy in carcinoma gallbladder (GBC) but may be associated with complications. We aimed to study the outcomes, complications and changes in quality of life in patients with GBC undergoing PTBD.

Methods: A prospective study from July 2018 to December 2019 in patients of GBC presenting with obstructive jaundice was done. Patients planned for PTBD were included in the study. The progression of disease, complications of PTBD, re-interventions, effects on initiation or completion of chemotherapy, surgical resection or intervention, overall survival was recorded. Quality of life (QoL) was assessed using SF-36 questionnaire before and after 4-6 weeks of intervention.

Results: Of 160 patients assessed for inclusion, 60 (mean age: $53.7 \pm 10.95$ years, 27 (45\%) males) were eventually included. Eleven patients (18.3\%) had metastatic disease at presentation. Of 60 patients undergoing PTBD, none had immediate procedure related complications, 41(68\%) patients had at-least one and $18(30 \%)$ patients had more than one complication. The most common complication was pericatheter bile leak (41.6\%) followed by catheter dislodgement (30\%), blockage (23.3 \%) and bleeding (10 $\%)$. Re-intervention was required in $32(53 \%)$ of patients. There was a significant decrease in QoL after PTBD $(P<0.0001)$. Median survival after PTBD was 12 weeks.

Conclusion: The high technical success of PTBD does not translate into the improvement of QoL, survival, and curative surgical treatment.

\section{Introduction}

Gallbladder cancer (GBC) is associated with poor prognosis with an overall survival ranging from only 5$20 \% .{ }^{1,2}$ Jaundice is an ominous sign in GBC and is present in $30-60 \%$ of patients at the time of presentation. ${ }^{3-5}$ The jaundice in carcinoma gallbladder is due to one of the following reasons: a) invasion of the common bile duct (CBD) by a mass in the neck of gallbladder $b$ ) invasion of the hilum by an infiltrating mass $\mathrm{c}$ ) lymph node compression d) intraluminal tumor extension e) extensive liver metastasis or due to an incidental stone in the CBD. ${ }^{6-8}$

Most patients presenting with jaundice are not amenable to a curative surgical resection, hence effective palliation plays a main role in the management of these patients. ${ }^{8-12}$ Biliary drainage is the most important method of palliation, especially in patients with persistent pruritus, anorexia, and cholangitis. Majority of the patients who are candidates for surgical resection in GBC with jaundice require preoperative drainage for optimization of liver function. Biliary drainage can be achieved through percutaneous trans-hepatic biliary drainage (PTBD), endoscopic biliary drainage (EBD) and surgical bypass. Surgical bypass is less preferred due to invasiveness of the procedure, and EBD or PTBD is carried out in the majority of the cases. ${ }^{13}$ Endoscopic drainage is more technically demanding and associated with higher incidence of cholangitis and the success rate varies from $40 \%-80 \%$ in hilar 
obstructions. ${ }^{14-16}$ In many centers PTBD is a preferred approach for proximal or hilar obstruction. ${ }^{17}$ PTBD is effective drainage methods but associated with significant complications that includes occlusion, dislodgement, cholangitis, peri catheter leakage and bleeding. These complications are possibly underreported in the literature. ${ }^{10,18,19}$ Though PTBD is preferred method for palliation but there is limited literature with conflicting results on its associated complications and impact on quality of life (QoL). ${ }^{17}$

Therefore, we conducted a prospective study to determine the outcome, overall complications as well as the quality of life (QoL) after PTBD in carcinoma gallbladder patients presenting with obstructive jaundice.

\section{Material And Methods}

\section{Study design and patient population}

This study is a prospective observational study and conducted at a tertiary care center in northern India. The study protocol was approved by the institute ethical committee before the recruitment of patients. Written informed consent was obtained from each participant prior to inclusion. We enrolled patients with obstructive jaundice due to carcinoma gallbladder presenting to us during the period of July 2018 to December 2019. Clinico-demographic features including comorbid conditions and preoperative laboratory parameters were recorded. All patients underwent preoperative staging with cross-sectional imaging (Contrast enhanced computed tomography (CECT) abdomen or Magnetic resonance imaging (MRI) or Positron emission tomography (PET- CT)). The diagnosis of carcinoma gallbladder was based on clinical and radiological features. Tissue biopsy was done in patients who were planned for neoadjuvant or palliative chemotherapy. Staging was done as per AJCC 8th edition. ${ }^{20}$

All patients underwent PTBD and the common indications of PTBD were a) cholangitis $b$ ) intractable pruritus $\mathrm{c}$ ) patients planned for curative surgery with bilirubin level $\geq 5 \mathrm{mg} / \mathrm{dl}$ or poor nutritional status or impaired renal parameters or coagulation abnormalities d) patients planned for neo adjuvant therapy e) palliative chemotherapy. Patients with benign etiology of jaundice e.g. choledocholithiasis, previously treated for carcinoma gallbladder, patients who underwent endoscopic drainage and those who refused to participate in the study were excluded.

\section{PTBD Procedure:}

All the baseline investigations including hemoglobin, blood cell counts, serum electrolytes, renal function test, liver function tests were done. All patients received injectable prophylactic antibiotic Piperacillin + Tazobactam 2 hours before the procedure.

All of the procedures were performed under local anesthesia using $2 \%$ of injection lignocaine. Under USG guidance a peripheral bile duct was punctured using $18 \mathrm{G}$ or a $21 \mathrm{G}$ puncture needle. After the free flow of bile through the puncture needle, 2-3 ml of diluted contrast material (Omnipaque $50 \%$ dilution with normal saline) was gently injected under fluoroscopic guidance to visualize the ductal anatomy and the 
level of biliary obstruction. PTBD catheter (8F or 10F single pigtail) was placed over guidewire in the ductal system after track dilatation. Left ductal system access was preferred over right system. Patients were observed for a minimum 24 hours or more when needed and then discharged. The bile from the PTBD catheter was sent for culture with antimicrobial sensitivity. Internalization of PTBD was attempted after 3 days or after complete resolution of cholangitis.

\section{Post PTBD Follow-up And Outcomes}

Patients with potentially resectable disease were further investigated. Those who were planned for neoadjuvant or palliative chemotherapy were started on chemotherapy. Patients were followed up in the outpatient clinic and PTBD related complications and re-intervention were recorded and managed.

\section{Assessment Of Quality Of Life}

We compared the quality of life of the patients included in our study before placing the PTBD catheter and after 4 to 6 weeks post procedure using the SF-36 questionnaire. ${ }^{21}$ The patients were questioned about various aspects of their quality of life using a set of 36 questions which were sub grouped into 9 topics namely, role limitations due to physical health, role limitations due to emotional problems, physical functioning, emotional well-being, social functioning, energy/ fatigue, general health, pain and health change.

\section{Statistical Analysis}

The data was analyzed with the SPSS version 22.0 software. Continuous variables were expressed as arithmetic mean \pm standard deviation (SD) or median (range), and they were equated using Students Paired T Test and Wilcoxon signed rank test wherever necessary. P-value was taken as statistically significant if it was less than 0.05 .

\section{Results}

\section{Study population}

During the study period total 160 patients of carcinoma gall bladder were assessed for inclusion. Eightynine patients of GBC without jaundice, 8 patients who underwent endoscopic drainage and 3 patients who declined to participate in the study were excluded (Fig. 1). A total of 60 patients were included in final analysis.

The clinico- demographic detail of study population is summarized in Table 1. The mean age of study population was $53.7 \pm 10.95$ years, $27(45 \%)$ were male. Eleven patients $(18.3 \%)$ had metastatic disease at the time of presentation. The clinical presentation was with abdominal pain in $48(80 \%)$ and fever in 21 patients (35\%). The gall bladder lump was palpable in $33(55 \%)$ patients and $2(3.3 \%)$ had ascites. 
Table 1

Clinico-Demographic detail of study population

\begin{tabular}{|ll|}
\hline Total number of patients & 60 \\
\hline Age, mean \pm SD, years & $53.7 \pm 10.95$ \\
\hline Gender, male, $\mathrm{n}(\%)$ & $27(45)$ \\
\hline BMI, mean \pm SD, $\mathrm{Kg} / \mathrm{m}^{2}$ & $21.88 \pm 2.57$ \\
\hline Clinical Presentation & $21(35)$ \\
Fever, $\mathrm{n}(\%)$ & $48(80)$ \\
Abdominal Pain, $\mathrm{n}(\%)$ & $33(55)$ \\
Palpable abdominal mass, $\mathrm{n}(\%)$ & $23(38)$ \\
Pruritus, $\mathrm{n}(\%)$ & $2(3)$ \\
Left supraclavicular lymphadenopathy (LSCL), $\mathrm{n}(\%)$ & \\
\hline Associated gall stone disease, $\mathrm{n}(\%)$ & $36(60)$ \\
\hline Comorbidity & $2(3)$ \\
Hypertension, $\mathrm{n}(\%)$ & $4(6)$ \\
Diabetes mellitus, $\mathrm{n}(\%)$ & \\
\hline Staging & $38(63)$ \\
T3 disease, $\mathrm{n}(\%)$ & $22(36)$ \\
T4 disease, $\mathrm{n}(\%)$ & $11(18)$ \\
Metastatic disease, $\mathrm{n}(\%)$ & \\
\hline
\end{tabular}

\section{PTBD Procedure And Its Complication:}

The left sided PTBD was placed in 59 (98.3\%) patients. Eight french (Fr) PTBD catheter was used in 59 $(98.3 \%)$ patients and $10 \mathrm{Fr}$ in one patient (1.6\%). On follow up there was significant decrease in the bilirubin level at 6 week post procedure $(14.94 \pm 6.24$ vs $7.51 \pm 4.33, P=<0.001)$. The successful internalization of PTBD was done in $40(67 \%)$ patients. No patient had immediate procedure related complications. Forty-one (68\%) had at least one complication following PTBD procedure. Eighteen (30\%) patients had more than one complication (Table 2). Re-intervention was required in 32 (53\%) of patients. Out of these 32 patients, re-intervention was required twice in eight patients and thrice in two patients. The indications and complications of PTBD procedure is enumerated in Table 2. The most common complication was peri-catheter bile leak in $25(41.6 \%)$ patients and post PTBD bleeding was seen in 
$6(10 \%)$ patients. Three out of these six patients required size upgradation of PTBD catheter to manage bleeding and the rest three did not require any intervention.

Table 2

Indications and complications of PTBD procedure:

\begin{tabular}{|lll|}
\hline \multicolumn{2}{|l|}{ Indications } \\
\hline 1 & Cholangitis, $\mathrm{n}(\%)$ & $21(35)$ \\
\hline 2 & Intractable pruritus, $\mathrm{n}(\%)$ & $23(38)$ \\
\hline 3 & Planned neo-adjuvant treatment, $\mathrm{n}(\%)$ & $19(31)$ \\
\hline 4 & Metastasis, $\mathrm{n}(\%)$ & $11(18)$ \\
\hline & Complications & \\
\hline 1 & Blockage of catheter, $\mathrm{n}(\%)$ & $14(23.3)$ \\
\hline 2 & Peri-catheter bile leak, $\mathrm{n}(\%)$ & $25(41.6)$ \\
\hline 3 & Catheter slip out, $\mathrm{n}(\%)$ & $18(30)$ \\
\hline 4 & Bleeding, $\mathrm{n}(\%)$ & $6(10)$ \\
\hline
\end{tabular}

\section{Follow Up Results:}

The median follow up of the study population was 11.8 weeks with no PTBD complication related mortality. Preoperative neoadjuvant or palliative chemotherapy was started in 7 patients. Only one patient completed the full course of planned chemotherapy, while in the rest chemotherapy could not be completed due to PTBD related complications or poor functional status. Two patients were planned for surgical exploration. One patient underwent right extended hepatectomy with hepatic duct resection and Roux - en - Y left hepaticojejunostomy. In another patient resection was abandoned due to metastatic disease on staging laparoscopic. Thirty-seven (61\%) patients expired within 6 months of diagnosis.

\section{Bile Culture:}

PTBD bile cultures were sent immediately after the procedure. Eight (13\%) patients had positive bile cultures and E. coli was the most common (50\%) microorganism isolated from the bile. Six patients developed post PTBD cholangitis, which was managed with intravenous antibiotics and additionally two patients required PTBD catheter change due to partial blockage.

\section{Quality Of Life Score:}

All patients underwent QoL assessment before and after the PTBD placement. There was significant decrease in the quality of life (SF - 36) of the patients in all of the nine categories after PTBD catheter 
placement. (Table 3).

Table 3

Quality of Life Score

\begin{tabular}{|c|c|c|c|c|}
\hline & Parameter & $\begin{array}{l}\text { Before PTBD } \\
\text { placement }\end{array}$ & $\begin{array}{l}\text { After PTBD } \\
\text { placement }\end{array}$ & $\begin{array}{l}P \\
\text { value }\end{array}$ \\
\hline 1 & Physical Functioning, mean \pm SD & $62.16 \pm 18.78$ & $28.25 \pm 16.25$ & $\begin{array}{l}<.001 \\
0.01\end{array}$ \\
\hline 2 & $\begin{array}{l}\text { Role limitations due to physical health, } \\
\text { mean } \pm \text { SD }\end{array}$ & $60.83 \pm 25.36$ & $17.16 \pm 18.04$ & $<.001$ \\
\hline 3 & $\begin{array}{l}\text { Role limitations due to emotional problems, } \\
\text { mean } \pm \text { SD }\end{array}$ & $41.38 \pm 27.25$ & $14.99 \pm 22.47$ & $<.001$ \\
\hline 4 & Energy / Fatigue, mean \pm SD & $58.66 \pm 10.53$ & $22.58 \pm 10.59$ & $\begin{array}{l}<.001 \\
0.001\end{array}$ \\
\hline 5 & Emotional wellbeing, mean \pm SD & $59.50 \pm 11.48$ & $25.01 \pm 10.38$ & $\begin{array}{l}<.001 \\
0.001\end{array}$ \\
\hline 6 & Social functioning, mean \pm SD & $53.45 \pm 14.57$ & $24.37 \pm 12.27$ & $\dot{0} 001$ \\
\hline 7 & Pain, mean \pm SD & $55.33 \pm 13.92$ & $16.58 \pm 19.06$ & $<.001$ \\
\hline 8 & General health, mean \pm SD & $46.08 \pm 10.24$ & $16.75 \pm 8.22$ & $<.001$ \\
\hline 9 & Health change, mean $\pm S D$ & $44.58 \pm 18.46$ & $13.75 \pm 13.36$ & $\begin{array}{l}<.001 \\
0.001\end{array}$ \\
\hline
\end{tabular}

\section{Discussion}

The present study demonstrates that percutaneous transhepatic biliary drainage is a common procedure used to relieve obstructive jaundice in malignant biliary obstruction secondary to carcinoma gallbladder and is an effective modality to improve the hyperbilirubinemia. The common indications of biliary drainage were palliation of symptoms, cholangitis, planned major liver resection and chemotherapy. However, this comes with a significant rate of complications and does not improve the QoL of these patients. The post PTBD overall median survival was 12 weeks. The study points to a need to improve biliary drainage techniques and post PTBD care, which may reduce the complication rates.

With the advent of minimally invasive techniques, PTBD and ERCP are well established and effective methods of biliary drainage. PTBD is preferred procedure in proximal obstruction and it increases the success of biliary drainage and reduce the risk of cholangitis. ${ }^{22}$ It can be done under minimal sedation, hence feasible in unstable patients also. ${ }^{13,23}$ Unfortunately, the procedure is associated with complication 
rates of $40-50 \%$ in retrospective studies with occlusion, dislodgement, cholangitis and peri-catheter leak being the most frequently reported complications. ${ }^{18,24}$ In our study, at least one PTBD related complication was observed in $68 \%$ of patients. Peri-catheter bile leak (41.6\%), catheter slip out (30\%), catheter blockage $(23.3 \%)$ were the common complications. The hanging external PTBD catheter and catheter blockage are important risk factor for majority of these complications. The early internalization of PTBD catheter in the absence of cholangitis and flushing of catheter with normal saline and appropriate post PTBD care might help in mitigating these complications.

A randomized study compared PTBD procedure with ERC drainage in carcinoma gall bladder and showed improved outcome in the form of better success rate, low incidence of cholangitis but did not showed significant change in quality of life in PTBD group as compared to ERCP group. ${ }^{10}$ Various studies evaluated the QoL after PTBD in malignant hilar obstruction and showed significant decrease in quality of life after PTBD. ${ }^{22,25}$ However these studies are limited by heterogenous population with different etiology of hilar obstruction. In our study, which focused on patients with carcinoma gallbladder, the QoL decreased in all nine subcategories of SF-36 questionnaires after PTBD. The higher complication rate and increased number of re-intervention rates contributed to the significant decrease in QoL.

In our study, we were able to do curative resection in only one patient out of the seventeen patients who were planned for resection. The reported incidence of curative resection in carcinoma gallbladder with jaundice is $7-30 \% .5,7,8,26$ The low resection rate in GBC with jaundice is due to aggressive tumor behavior with high incidence of metastasis and further compounded by the complications associated with drainage procedure. In our study PTBD related complications and interventions delayed the initiation and completion of chemotherapy, contributing to the poor overall outcome. Despite these complications, PTBD has significant role in palliation and treatment of proximal biliary stricture. The provision of better post intervention care and patient education is crucial to decrease these complications. This is a major challenge in low income country with poor socioeconomic background of patient population.

To conclude, jaundiced patients with underlying carcinoma gallbladder have a higher incidence of locally advanced and metastatic disease. Biliary drainage procedure should be performed with the aims of relieving symptoms, improving QoL, and enabling further chemotherapy treatments. The higher technical success rate of PTBD does not translate into the improvements of QoL, median survival, and rates of curative surgical treatment in carcinoma gall bladder. The role of PTBD merely as a palliative procedure because of morbidity associated with the procedure and lack of improvement in QoL. However, improved technical expertise, drainage techniques and adequate post procedural care of PTBD might help in improving the outcomes.

\section{Declarations}

Funding - No funding taken from any agency or organization

Conflicts of interest/Competing interests - none 
Availability of data and material- available

Code availability - NA

Ethics approval - Taken from institute ethical committee

Consent to participate - Taken from all participant

Consent for publication - NA

\section{References}

1. Takada $T$, Amano $H$, Yasuda $H$, Nimura $Y$, Matsushiro $T$, et al. Is postoperative adjuvant chemotherapy useful for gallbladder carcinoma? A Phase III multicenter prospective randomized controlled trial in patients with resected pancreaticobiliary carcinoma. Cancer. 2002; 95:1685-95.

2. Mayo SC, Shore AD, Nathan H, Edil B, Wolfgang CL, Hirose $K$, et al. National Trends in the Management and Survival of Surgically Managed Gallbladder Adenocarcinoma Over 15 years: A Population-Based Analysis. J Gastrointest Surg. 2010; 14:1578-91.

3. D'Angelica M, Dalal KM, DeMatteo RP, Fong Y, Blumgart LH, Jarnagin WR. Analysis of the Extent of Resection for Adenocarcinoma of the Gallbladder. Ann Surg Oncol. 2009; 16:806-16.

4. Grobmyer SR, Lieberman MD, Daly JM. Gallbladder Cancer in the Twentieth Century: Single Institutions Experience. World J Surg. 2004 1; 28:47-9.

5. Hawkins WG, DeMatteo RP, Jarnagin WR, Ben-Porat L, Blumgart LH, Fong Y. Jaundice Predicts Advanced Disease and Early Mortality in Patients with Gallbladder Cancer. Ann Surg Oncol. 2004; 11:310-5.

6. Redaelli C, Buchler MW, Schiiing MK, KrahenbuhI L, Ruchti C, Blumgart LH, et al. High coincidence of Mirizzi syndrome and gallbladder carcinoma. Surgery 1997; 121:58-63.

7. Tran TB, Norton JA, Ethun CG, Pawlik TM, Buettner S, Schmidt C, et al. Gallbladder Cancer Presenting with Jaundice: Uniformly Fatal or Still Potentially Curable? J Gastrointest Surg. 2017; 21:1245-53.

8. Mishra PK, Saluja SS, Prithiviraj N, Varshney V, Goel N, Patil N. Predictors of curative resection and long term survival of gallbladder cancer - A retrospective analysis. Am J Surg. 2017; 214:278-86.

9. Agarwal AK, Mandal S, Singh S, Bhojwani R, Sakhuja P, Uppal R. Biliary Obstruction in Gall Bladder Cancer Is Not Sine Qua Non of Inoperability. Ann Surg Oncol.2007;14:2831-7.

10. Saluja S, Gulati M, Garg P, Pal H, Pal S, Sahni P, et al. Endoscopic or Percutaneous Biliary Drainage for Gallbladder Cancer: A Randomized Trial and Quality of Life Assessment. Clin Gastroenterol Hepatol. 2008; 6:944-950.

11. Nishio H, Ebata T, Yokoyama Y, Igami T, Sugawara G, Nagino M. Gallbladder Cancer Involving the Extrahepatic Bile Duct is Worthy of Resection: Ann Surg. $2011 ; 253: 953-60$.

12. Regimbeau JM, Fuks D, Bachellier $P$, Le Treut YP, Pruvot FR, Navarro F, et al. Prognostic value of jaundice in patients with gallbladder cancer by the AFC-GBC-2009 study group. Eur J Surg Oncol 
EJSO. $2011 ; 37: 505-12$.

13. Moole H, Dharmapuri S, Duvvuri A, Dharmapuri S, Boddireddy R, Moole V, et al. Endoscopic versus Percutaneous Biliary Drainage in Palliation of Advanced Malignant Hilar Obstruction: A MetaAnalysis and Systematic Review. Can J Gastroenterol Hepatol. 2016; 2016:1-8.

14. Sherman S. Endoscopic drainage of malignant hilar obstruction: Is one biliary stent enough or should we work to place two? Gastrointest Endosc. 2001; 53:681-4.

15. Walter T, Ho CS, Horgan AM, Warkentin A, Gallinger S, Greig PD, et al. Endoscopic or Percutaneous Biliary Drainage for Klatskin Tumors? J Vasc Interv Radiol. 2013; 24:113-21.

16. Paik WH, Park YS, Hwang J-H, Lee SH, Yoon CJ, Kang S-G, et al. Palliative treatment with selfexpandable metallic stents in patients with advanced type III or IV hilar cholangiocarcinoma: a percutaneous versus endoscopic approach. Gastrointest Endosc. 2009; 69:55-62.

17. Crosara Teixeira M, Mak MP, Marques DF, Capareli F, Carnevale FC, Moreira AM, et al. Percutaneous Transhepatic Biliary Drainage in Patients with Advanced Solid Malignancies: Prognostic Factors and Clinical Outcomes. J Gastrointest Cancer. 2013; 44:398-403.

18. Nennstiel S, Weber A, Frick G, Haller B, Meining A, Schmid RM, et al. Drainage-related Complications in Percutaneous Transhepatic Biliary Drainage: An Analysis Over 10 Years. J Clin Gastroenterol. 2015; 49:764-70.

19. Chu D, Adler DG. Malignant Biliary Tract Obstruction: Evaluation and Therapy. J Natl Compr Canc Netw. 2010; 8:1033-44.

20. Amin MB, Gress DM, Meyer LR, Edge SB, Greene FL, Byrd DR, et al. AJCC Cancer Staging Manual, 8 ed., Springer, New York, 2017.

21. Ware Jr JE, Sherbourne CD. The MOS 36-item short-form health survey (SF- 36). I. Conceptual framework and item selection. Medical care.1992; 30:473-83.

22. Mansfield S. Management of hilar cholangiocarcinoma in the North of England: Pathology, treatment, and outcome. World J Gastroenterol. 2005; 11:7625

23. Gupta P, Maralakunte M, Rathee S, Samanta J, Sharma V, Mandavdhare H et al, Percutaneous transhepatic biliary drainage in patients at higher risk for adverse events: experience from a tertiary care referral center. Abdom Radiol (NY). 2020; 45:2547-53.

24. Knap D, Orlecka N, Judka R, Juza A, Drabek M, Honkowicz M, et al. Biliary duct obstruction treatment with aid of percutaneous transhepatic biliary drainage. Alex J Med. 2016; 52:185-91.

25. Robson PC, Heffernan N, Gonen M, Thornton R, Brody LA, Holmes R, et al. Prospective Study of Outcomes after Percutaneous Biliary Drainage for Malignant Biliary Obstruction. Ann Surg Oncol. 2010; 17:2303-11.

26. Dasari BVM, Ionescu MI, Pawlik TM, Hodson J, Sutcliffe RP, Roberts KJ, et al. Outcomes of surgical resection of gallbladder cancer in patients presenting with jaundice: A systematic review and metaanalysis. J Surg Oncol. 2018; 118:477-85. 
Figures

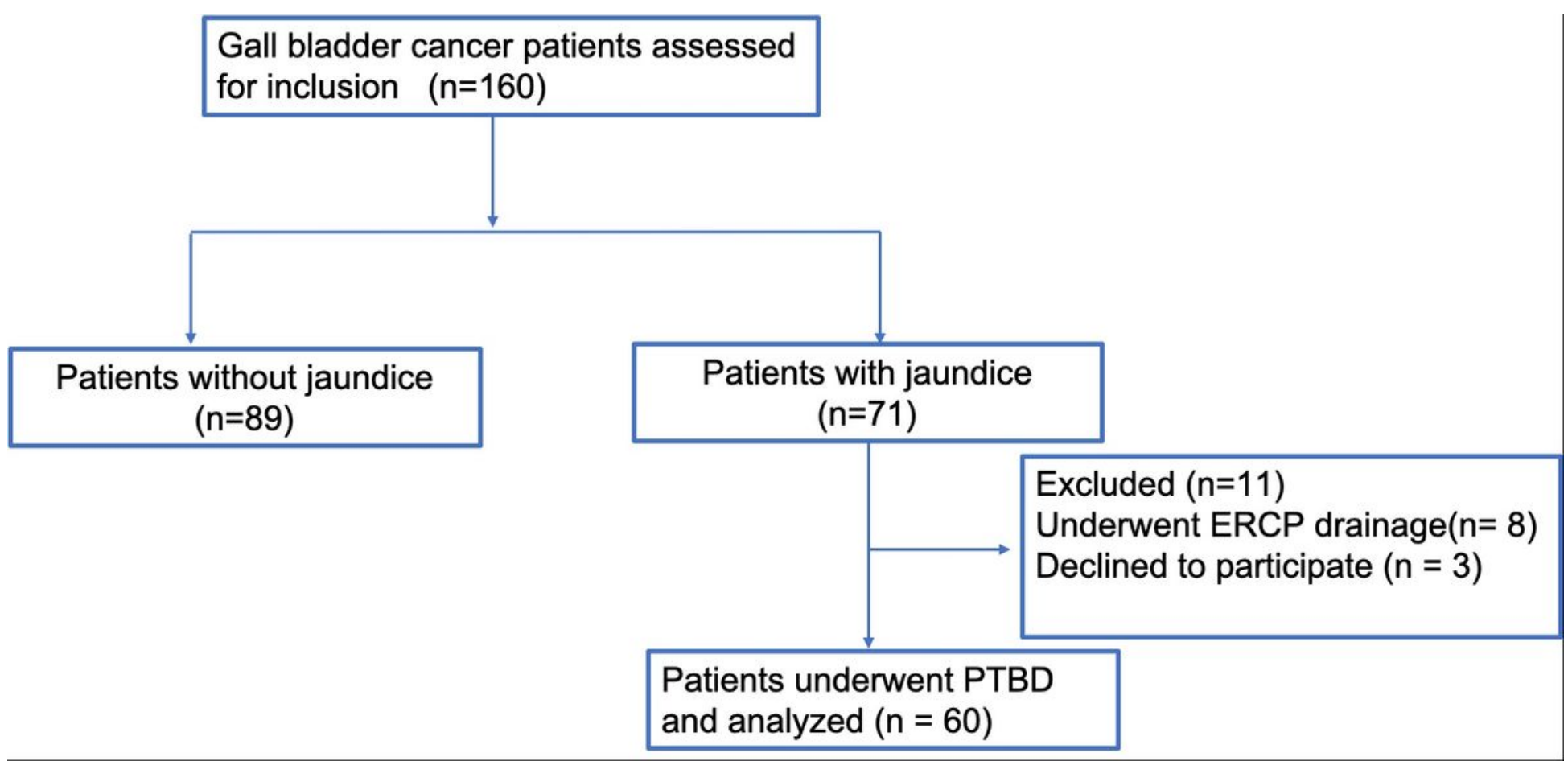

Figure 1

Flow chart of the study population 